\title{
TESTICULAR DEVELOPMENT IN THE MUSCOVY DUCK (CAIRINA MOSCHATA)
}

\author{
V. GERZILOV ${ }^{1}$, A. BOCHUKOV ${ }^{1}$, G. PENCHEV ${ }^{2} \&$ P. PETROV ${ }^{1}$ \\ ${ }^{1}$ Department of Animal Science, Faculty of Agronomy, Agricultural University, \\ Plovdiv, Bulgaria; ${ }^{2}$ Department of Veterinary Anatomy, Histology and Embryology, \\ Faculty of Veterinary Medicine, Trakia University, Stara Zagora, Bulgaria
}

\section{Summary}

Gerzilov, V., A. Bochukov, G. Penchev \& P. Petrov, 2016. Testicular development in the Muscovy duck (Cairina moschata). Bulg. J. Vet. Med., 19, No 1, 8-18.

\begin{abstract}
Morphometrical and histological examination of Muscovy drakes' testes was performed at 13 different ages: at 1 and 15 days of age, at 1, 2, 3, 4, 5, 6, 7, 8, 12, 18 and 24 months of age. The testes of three birds were examined at each age period. The testicular morphometry at the respective age included the following parameters - weight, length and width, diameter of seminiferous tubules (ST), ratio between ST volume and interstitial connective tissue volume. Immediately after hatching, there were two cell types in seminiferous tubular wall - Sertoli cells (Epitheliocytus sustentans) and spermatogonia. At 2 months of age, spermatogonia formed one row in ST with lumen and the spermatogenesis has started. At 5 months of age, all generations of germ cells were present in ST. After that age, the histological picture is the typical one for the testis of a sexually mature bird. Morphometric findings were as followed: after the $2^{\text {nd }}$ month of age, the increase in testes weight and ST diameter became more pronounced at each subsequent age period. During the breeding period (at 8-12 months of age and at 2 years of age), the weight and size of testes were the greatest. From hatch to 1 month of age, the interstitial tissue (IT) prevailed over ST, whereas at age periods that followed, the opposite relationship was observed. During the non-breeding period (18 months of age) the testicular parenchyma regressed resulting in lower testes weight, lower ST diameter and volume and presence of spermatogonia only in ST lumen. The weight and size of testes was identical to that of birds at 4 months of age.
\end{abstract}

Key words: age, histlology, morphometry, Muscovy duck (Cairina moschata), testes

\section{INTRODUCTION}

The reproduction of birds is guided by internal physiological events, which together with environmental factors (light day duration, temperature, availability of food) have a direct effect on the gonadal status and function (Bowles, 2014).
The reproduction capacity of male birds is variable, the spermatogenesis and maturation of spermatozoa being substantially influenced by endocrine, paracrine and nervous factors (Kirby, 1996). 
The amount and quality of avian semen varies with seasons. The exposure to extreme temperatures could limit the reproduction of birds, and severe temperature fluctuations could often result in reduced production of spermatozoa (Kundu \& Panda, 1990; Mirande et al., 1996). The size, shape and viability of spermatozoa in birds are largely dependent by the size of testes and the spermatogenous tissue amount (Lupold et al., 2009).

In birds, considerable seasonal changes in testicular weight and development are observed (Lofts \& Murton, 1973). In sexually mature birds, testes are significantly enlarged during the breeding period. Different investigations on the development, weight, morphometry and histology of testes have been performed in some domestic poultry: roosters (Marvan, 1969; Rothwell \& Tingari, 1973; Rothwell, 1975; Trefil et al., 2006; Aire \& Ozegbe, 2007; Bull et al., 2007), muscovy ducks (Marchand \& Gomot, 1973; Gerzilov et al., 2002; Islam et al., 2013), geese (Mori \& George, 1978; Halse, 1985), turkeys (Noirault, 2006; Aire \& Ozegbe, 2007; Bakst, 2007), ducks (Aire \& Ozegbe, 2007; Elbajory et al., 2013), Japanese quails (Lin \& Jones, 1990; van Nassauw et al., 1993; Bochukov et al., 1995; Aire, 1997; Maretta \& Marettova, 2004; Al-Tememy, 2010) as well as in poultry intergeneric hybrids (Marchand \& Gomot, 1976; Castillo et al., 2012).

The examination of the changes in testicular tissue after hatching and at different time intervals assists in elucidating the normal status of the main structural components for each specific age (Bochukov et al., 1995).

The purpose of the present study was to investigate morphological and histological testicular features in Muscovy drakes.

\section{MATERIALS AND METHODS}

Morphometric and histological studies of Muscovy drakes' testes were done at 13 different ages at 1 and 15 days of age, at $1,2,3,4,5,6,7,8,12,18$ and 24 months of age. A total of 39 male birds were used; 3 for each age period. The birds from both genders were reared freely in groups in the poultry farm of the University of Agriculture on deep permanent litter with constant access to walking yards.

Upon reaching the respective age, the birds were individually weighed before the slaughter. Within $5 \mathrm{~min}$ after slaughter, both testes were removed and the following morphometric measurements were done on each testis: weight (g), length, lateral and dorsoabdominal width $(\mathrm{mm})$. Weight studies were performed by means of analytical OHAUS 2000 scales with precision of $0.01 \mathrm{~g}$. The length and both widths of testes were measured with a Vernier caliper with precision of $0.1 \mathrm{~mm}$.

Within the $15^{\text {th }}$ min after the slaughter, testes were fixed in fresh Bouin's solition for 72 hours as whole organs (in early ages) or parts of them (pieces of size $0.5 \times 0.5 \times 0.5 \mathrm{~cm})$. Then followed removal of the fixative in ascending alcohol series (sequentially immersing in $60,70 \%, 80 \%$, $90 \%, 96 \%$ ethanol and two times in absolute ethanol at room temperature for 30 min each), clearing with xylene, embedding in paraffin, cutting on a Reichert microtome, mounting of sections 6-7 $\mu \mathrm{m}$ thick on glass slides and staining with haematoxylin-eosin. Histological examinations were performed with Jenaval light microscope, and findings were documented with a CETI camera. The diameter of ST $(\mu \mathrm{m})$ was determined by measurements of approximately $30 \mathrm{ST}$ transverse sections using a standardised eyepiece micrometer. The relative volumes (\%) of ST and IT were determined by the method 
of Pakenas (1968) on the basis of 30 measurements per testis, using an ocular grid with four hairs of different length, located at specific intervals over the grid circle.

The results for the testicular morphometry are presented as mean \pm SEM. Statistical data processing was done using Student's $t$ test (StatMost for Windows) and the difference was considered significant when $\mathrm{P}$ values were less than 0.05 .

\section{RESULTS}

One-day old male ducklings possessed small and oval testes. These organs had a well-differentiated tunica albuginea. In their parenchyma, two primary components are present - ST and interstitial connective tissue (Fig. 1). The tunica albuginea was built of dense connective tissue and was relatively thin. In examined observation fields, there were no thick connective tissue stripes dividing the testis into lobules. The ST were slightly curved and mostly longitudinally cut. Their wall was composed of densely packed Sertoli cells (Epitheliocytus sustentans) and basement membrane, surrounded by welldeveloped peritubular tissue. Sertoli cell nuclei were small and oval. Their cytoplasm was acidophilic and filled the entire ST lumen, so the latter could not be identified. Within the seminiferous tubules, relatively large spermatogonia and big round nuclei were irregularly arranged. In some places within observation fields, anastomoses among the different ST were noticed. The interstitial connective tissue was with rich cellular content with prevalence of fibroblasts.

At the next two ages studied (15 and 30 days of age), the histological picture was comparable. The curvature of ST and the incidence of transversely cut tubules increased with age. The cellular composition of ST was similar to that in day-old ducklings, but in some areas, a cleft-like lumen has appeared (Fig. 2).

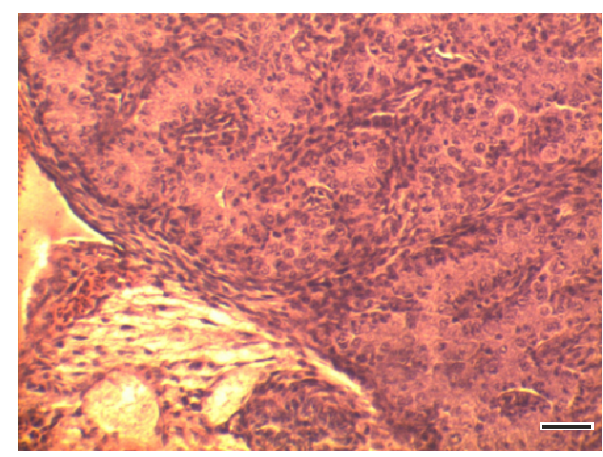

Fig. 1. Testis of 1-day-old Muscovy duckling. $\mathrm{H} / \mathrm{E}(\mathrm{bar}=50 \mu \mathrm{m})$.

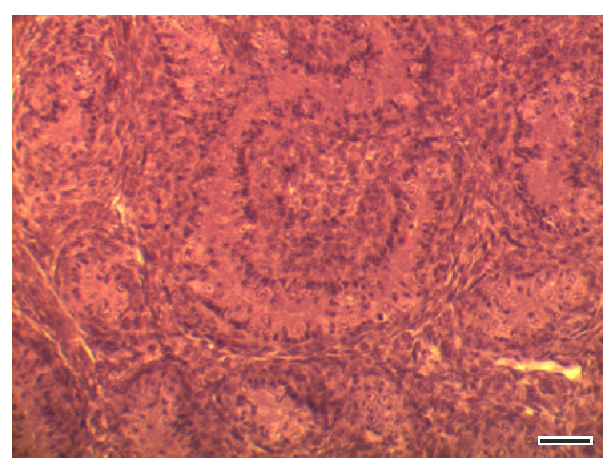

Fig. 2. Testis of 30-day-old Muscovy duckling. $\mathrm{H} / \mathrm{E}$ (bar=50 $\mu \mathrm{m})$.

At 2 months of age, ST and IT have underwent substantial changes. Transversely cut tubules with lumen prevailed, and germ cells formed one layer over the Sertoli cell nuclei. The interstitial space contained distinct groups of Leydig cells (Endocrinocytos interstitialis) with oval nucleus and acidophilic cytoplasm (Fig. 3).

At 3 months of age, an enhanced prevalence of germ cells in ST structure was established. They were arranged in two layers - a peripheral one, formed by spermatogonia and located adjacently to Ser- 


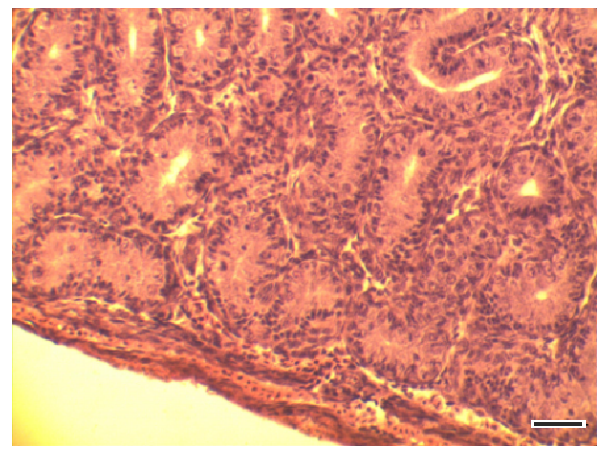

Fig. 3. Testis of 2-month-old Muscovy duckling. $\mathrm{H} / \mathrm{E}(\mathrm{bar}=50 \mu \mathrm{m})$.

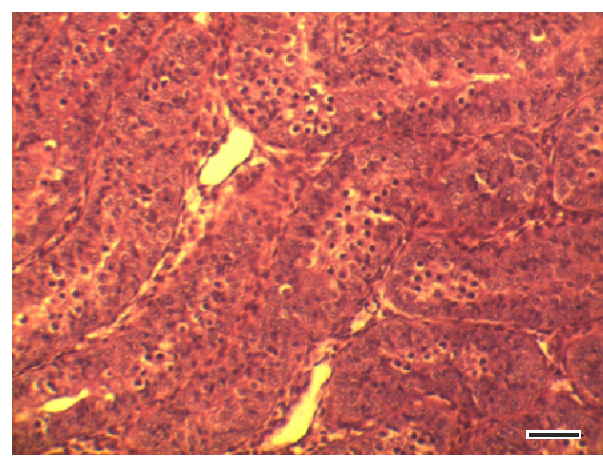

Fig. 4. Testis of 3-month-old Muscovy duckling. $\mathrm{H} / \mathrm{E}$ (bar=50 $\mu \mathrm{m})$.

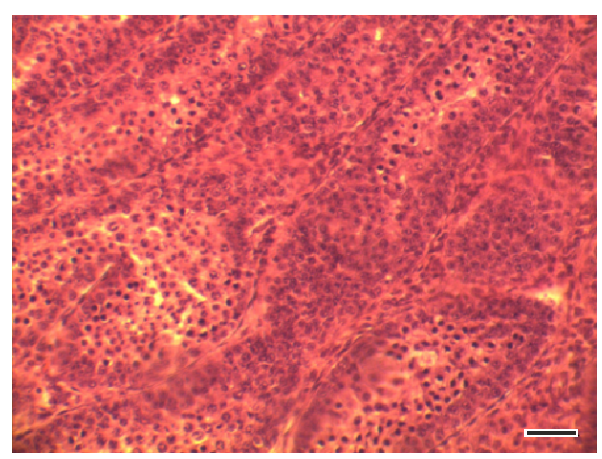

Fig. 5. Testis of 4-month-old Muscovy duckling. $\mathrm{H} / \mathrm{E}$ (bar=50 $\mu \mathrm{m})$.

toli cell nuclei. The second clearly distinguished layer of spermatocytes was situated near to the lumen. These cells were large, with oval nuclei and acidophilic cytoplasm. Some ST had a lumen, but in most of them it was occupied by germ cells. The IT appeared as thin bands or small triangular islets (Fig. 4).

At the age of 4 months, the changes in $\mathrm{ST}$ related to occurring spermatogenesis were persisting. Most ST contained 1-2 rows of spermatogonia, one row of spermatocytes and one row of prespermatids. Only in occasional parts of the ST, a small lumen was visible while the major part of them was occupied by the various existing generations of germ cells (Fig. 5). Fivemonth-old drakes exhibited a various histological picture of ST reflecting the occurrence of the various stages of spermatogenesis. In some areas, spermatozoa were observed, and most of them were not attached to Sertoli cells (Fig. 6). The lumen of ST was large, irregular, filled with spermatozoa and desquamated younger germ cell generations.

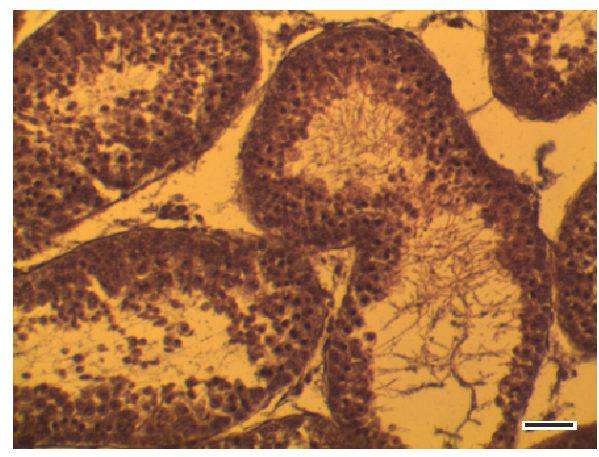

Fig. 6. Testis of 5-month-old Muscovy drake. $\mathrm{H} / \mathrm{E}(\mathrm{bar}=50 \mu \mathrm{m})$.

At the subsequent studied age periods until one year of age, the histological picture was similar showing features specific for sexually mature birds. In the major part of ST, a large amount of mature spermatozoa was present, attached as clusters to Sertoli cells. Only few were observed 
to be free in the lumen. The presence of groups of spermatozoa around Sertoli cells of the "wheat ear" type.

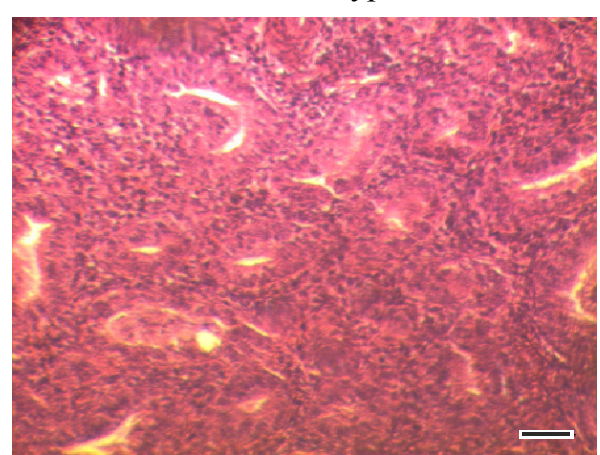

Fig. 7. Testis of 18-month-old Muscovy drake. $\mathrm{H} / \mathrm{E}(\mathrm{bar}=50 \mu \mathrm{m})$.

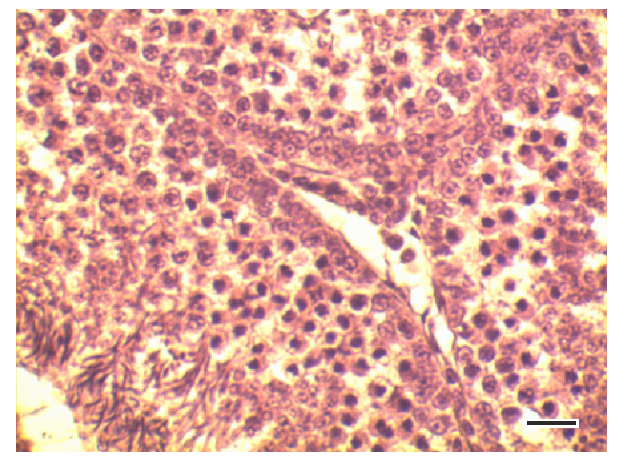

Fig. 8. Testis of 24-month-old Muscovy drake. $\mathrm{H} / \mathrm{E}(\mathrm{bar}=25 \mu \mathrm{m})$.

At 18 months of age (coinciding with the non-breeding period), clear regression signs of testicular parenchyma were demonstrated. Seminiferous tubules were in an inactive state. Their wall was built of Sertoli cells, to which only a single row of spermatogonia was attached. The other germ cell generations were absent. The tubules' lumen was relatively large and irregular. A higher prevalence of interstitial connective tissue was noticed (Fig. 7).

The histological picture at 24 months of age was specific for sexually mature birds. Seminiferous tubules exhibited con- figurations marking different stages of occurring spermatogenesis (Fig. 8).

The data of macroscopic testicular morphometry are presented in Table 1 . After 3 months of age, a marked increase in the weight of testes was observed, more pronounced after the $7^{\text {th }}$ months. In most instances (87.18\%) left testes were heavier than right ones. At 2 years of age, the weight of testes was 1.5-3 times higher than that of one-year-old drakes. The testicular weight showed significant difference between any two adjacent ages $(\mathrm{P}<0.05)$ without those of 4 and 5, 5 and 6 and 8 and 12 months of ages.

The changes in gonadosomatic index were logical and followed the time course of changes in testicular weight. At 18 months of age, the values of the index were low because of the reduced weight of testes but not of the body.

The data about seminiferous tubules' diameters are depicted in Fig. 9. During the first two weeks after hatching, this parameter was almost unchanged. Thereafter, the diameter of seminiferous tubules began to increase gradually with age. This tendency was preserved until the age of one year, and was followed by a sharp decrease in the diameter during the nonbreeding period. At 2 years of age, the diameter was the largest, which was the cause for the higher weight of testes at that age.

The volume ratios of both major components of testicular parenchyma (seminiferous tubules and interstitial tissue) are showed on Fig. 10. Until hatching up to 30 days of age, the IT was the predominant one. After that age, the opposite tendency was present - the volume of ST was higher than the interstitial volume. This tendency was maintained until 12 months of age, when the ST volume attained a peak value. At 18 months of age, a sub- 


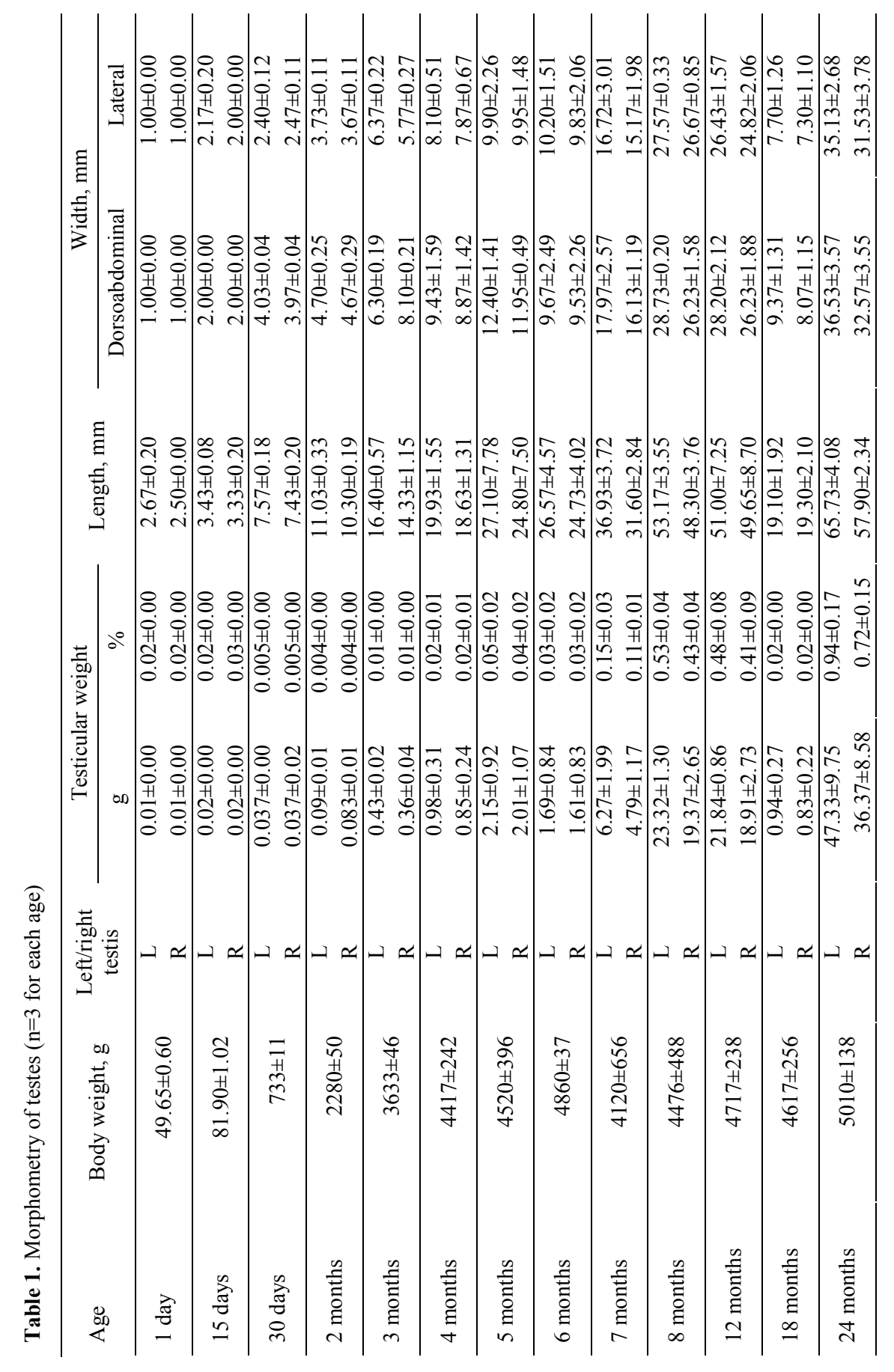

BJVM, 19, No 1 


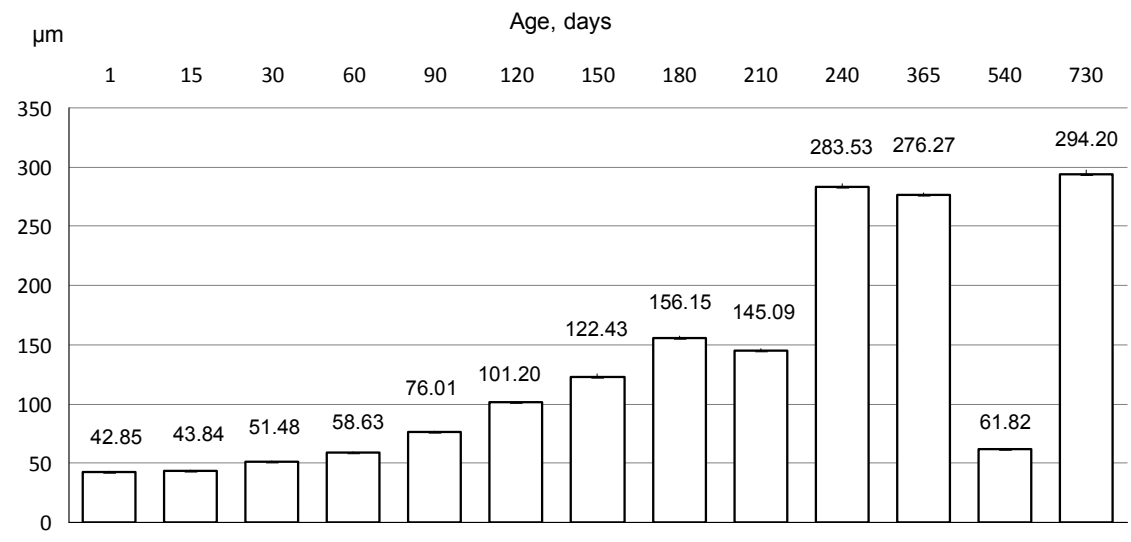

Fig. 9. Diameter of seminiferous tubules.

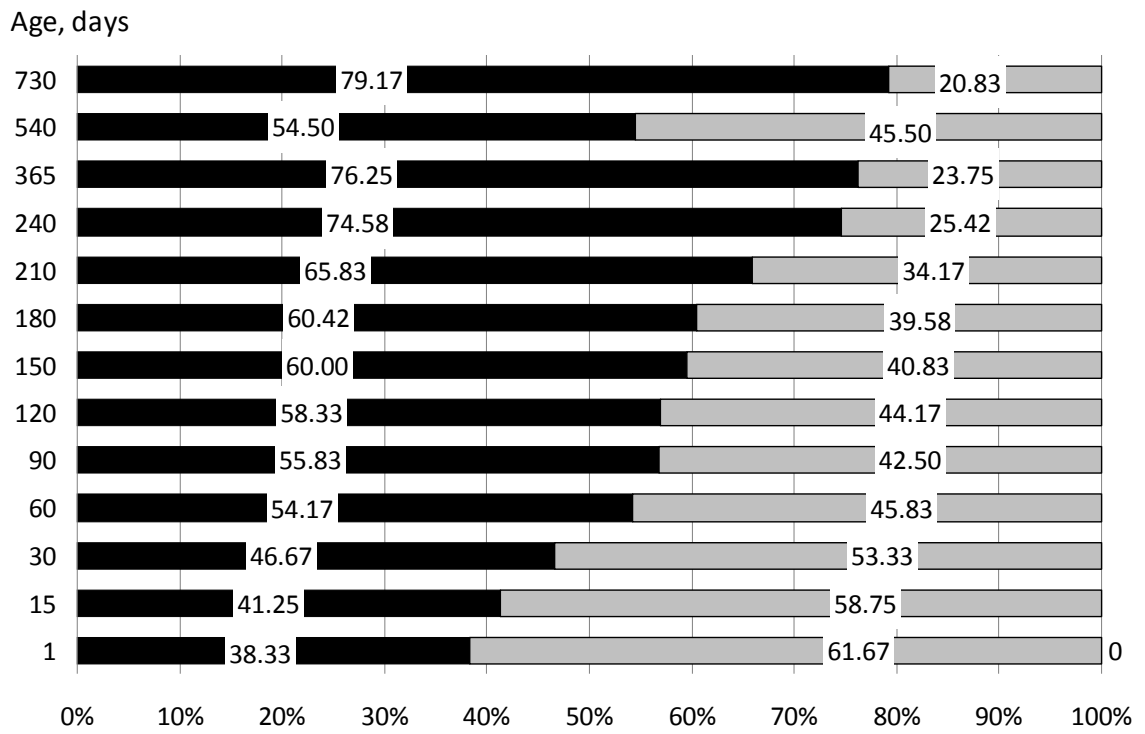

Fig. 10. Ratio of ST to interstitial connective tissue volumes.

stantial predominance of interstitial connective tissue on the account of lower ST volume was observed. At 24 months of age, the ratio returned to the range of values established in 12-month-old drakes.

\section{DISCUSSION}

The testicular structure of birds is from the tubular type, typical for all amniota.
The structure of the testicular capsule in Muscovy drakes was similar to that of other birds (Aire, 1997). Our study has demonstrated that immediately after hatching, the origins of the main components of testicular parenchyma - seminiferous tubules and interstitial connective tissue - were present. In accordance with Bowles (2014) we established lack of differentiated septa, dividing the organ into 
lobules. This histological picture has been observed in Japanese quails (Bochukov et al., 1995). The presence of anastomoses among the tubules is specific for birds, and this morphological feature is present at the very beginning of the individual development (Bowles, 2014). Anastomoses serve for the more intensive and abundant ejaculation of spermatozoa during the copulation. The seminiferous tubule's wall contains Sertoli cells, which are densely arranged and whose apical part occupies their central zone, and that is why the lumen is absent. The lumen appears at the age of 30 days. Almost along the entire length of seminiferous tubules, a cleft-like lumen is formed at 2 months of age. Then, spermatogonia formed one row over the Sertoli cells. In our opinion, the spermatogenesis in studied birds has started. In 3-months old ducklings, spermatozoa were already present. The other two germ cell generations - prespermatids and spermatids were established at 4 months of age, whereas mature spermatozoa were observed at 5 months of age - the sexual maturity has begun.

Islam (2013) reported the presence of all generations of germ cells at 6 months of age in domestic duck (Anas platyrhynchos) and Muscovy duck (Cairina moschata). After that, from the $6^{\text {th }}$ to the $12^{\text {th }}$ month of life, the changes were rather quantitative than qualitative. According to Bowles (2014) the testes change in size and colour in response to hormonal fluctuations (increasing serum concentrations of FSH and LH) that influence sexual activity. The increased size is a result of increased length and diameter of the seminiferous tubules, and numbers of Leydig or interstitial cells. The observed picture during that period and at 24 months of age was specific for birds in active breeding period, whose ST contained various combinations of germ cells, reflecting the different stages of the spermatogenesis in drakes described by Johnson (1961). The status of the seminiferous parenchyma at 18 months of age is attributed by us to atrophic changes in testes, occurring during the non-breeding period.

In available literature, there are no consistent data about the age-related main morphometric features of testes in Muscovy drakes. Weight measurements indicated that after hatching until 60 days of age, the testes enlargement was relatively slow. This was probably due to the slow tissue differentiation mainly in the seminiferous tubules. A similar picture was reported in Japanese quails as well (Bochukov et al., 1995). With the start of the spermatogenesis, the rate of this development became faster, and the weight of testes at 5 months of age, at sexual maturity, increased almost 20 times compared to the age of 60 days. After the onset of sexual maturity, the testes hypertrophied and their weight increased about 10 times at 12 months of age compared to that in 5month-old birds. During the non-breeding period, the weight of testes was significantly reduced and attained values usual for sexually immature bird. As a rule, during the entire experimental period, the left testis was heavier than the right counterpart. In birds with marked seasonal breeding pattern, the testes increased over about 45 days (Blanco et al., 2007).

In our study, we have found out that the increase in testicular weight was almost continuous up to 1 year of age (corresponding to the reproductive period), followed by atrophy and reaching maximum values in 2-year-old birds. The weight differences between the left and the right testis showed the presence of asymmetry, in agreement with data from 
other researchers (Calhim \& Birkhead, 2006; Denk \& Kempenaeres, 2006; Noirault et al., 2006). The reduction of weight during the non-breeding period confirmed the results of Johnson (1961) about lower weight of testes during the autumn and the winter compared to the breeding period.

The changes in seminiferous tubules' diameter were proportional to changes in testicular weight. During the first four examined age periods, the ST diameter increased gradually, but after the start of the spermatogenesis, the values of this parameter increased substantially and statistically significantly in each age group. At 18 months of life, ST diameter was similar to that in 2-month-old ducklings.

The investigation of the ratio of ST and interstitial volumes showed that immediately after hatching, the connective tissue volume was almost twice bigger than the spermatogenic one. This was observed until the start of spermatogenesis, where the ST volume was statistically significantly higher that the interstitial one. The values of this parameter in the Japanese quail immediately after hatching showed the reverse ratio (Bochukov et al., 1995). Afterwards, the ST volume exceeded considerably interstitial volume at all other studied ages, except for the nonbreeding period, where the ratio was again in favour of the connective tissue. The volume ratios between $\mathrm{ST}$ and interstitial connective tissue in sexually mature Muscovy drakes during the breeding period correlated to findings in Icteridae birds (Lupold et al., 2009). The enlarged ST volume was responsible for the seasonal hypertrophy of testes in birds (Pollock, 2002).

Microscopic morphometric measurements showed that the changes in the weight of testes were mainly due to the changes in ST diameter and volume.

\section{CONCLUSIONS}

The results of our studies indicated that the structure of testes of Cairina moschata was similar to that in other avian species. The observed histological picture from hatching to 2 years of age reflected the changes occurring in these organs with advancement of age and sexual activity start of spermatogenesis at 2 months of age and presence of all generations of germ cells in ST at 5 months of age. Morphometric studied reflected the agerelated and seasonal differences which were logically associated. The weight and size of testes were the greatest during the reproduction period from the $8^{\text {th }}$ to the $12^{\text {th }}$ month of age and at 24 months of age. At 18 months of age, their weight and size was similar to those in 4-month-old birds, and the ST lumen was similar to than at 2 months of age.

\section{REFERENCES}

Aire, T. \& P. Ozegbe, 2007. The testicular capsule and peritubular tissue of birds: morphometry, histology, ultrastructure and immunohistochemistry. Journal of Anatomy, 210, 731-740.

Aire, A., 1997. The structure of the interstitial tissue of the active and resting avian testis. Onderstepoort Journal of Veterinary Research, 64, 291-299.

Al-Tememy, H., 2010. Histological study of testis in quail (Coturnix coturnix japonica). Al-Anbar Journal Veterinary Sciences, 3, 36-44.

Bakst, M. R., V. Akuffo, P. Trefil \& J. P. Brillard, 2007. Morphological and histochemical characterization of the seminiferous epithelial and Leydig cells of the turkey. Animal Reproduction Science, 97, 303-313.

Blanco, J., J. Samour \& D. M. Bird, 2007. Reproductive physiology. In: Raptor Re- 
search and Management Techniques, eds. D.M. Bird \& K.L. Bildstein, Hancock House Publishers, Surrey, British Columbia, Canada, pp. 286-292.

Bochukov, A., R. Michailov, S. Ribarski \& G. Penchev, 1995. Histological changes in testes of Japanese quail (Coturnix coturnix japonica) from hatching to 120 days. Veterinary Medicine, 1, 133-137 (BG).

Bowles, H. L., 2014. Evaluating and treating the reproductive system. Clinical Avian Medicine, 18, 519-539.

Bull, M. L., M. R. F. B. Martins, M. D. Cesário, C. R. Padovani \& A. A. Mendes, 2007. Anatomical study on domestical fowl (Gallus domesticus) reproductive system. International Journal of Morphology, 25, 709-716.

Calhim, S. \& T. Birkhead, 2006. Testes size in birds: quality versus quantity - assumptions, errors and estimates. Behavioral Ecology, 10, 271-275.

Castillo A., M. Marzoni, A. Pirone \& I. Romboli, 2012. Histological observations in testes of hybrids of Gallus gallus x Phasianuns colchicus. Avian Biology Research, 5, 1-10

Denk, A. \& B. Kempenaeres, 2006. Testosterone and testes size in mallards (Anas platyrhynchos). Journal of Ornithology, 147, 436-440.

Elbajory, S. I. A., M. D. El Tingari \& M. A. Abdalla, 2013. Morphological study of the testis of adult Sudanese duck (Anas platyrhynchos). International Journal of Animal and Veterinary Advances, 5, 103-107.

Gerzilov, V., S. Vitanov, M. Nikolova \& I. Nikolov, 2002. Morphological and histological assessment of testes of Muscovy drakes producing ejaculates two-and threefold weekly. Animal Science (Sofia), 39, 119-123 (BG).

Halse. A., 1985. Gonadal cycles and levels of luteinizing hormone in wild spur-winged gees, Plectropterus gambensis. Journal of Zoology, 205, 335-355.

Islam, F., S. Ishishita, Y. Uno, B. Mollah, K. Skrikulnath \& Y. Matsuda, 2013. Male hybrid sterility in the mule duck is associated with meiotic arrest in primary spermatocytes. Journal Poultry Science, 50, 311320.

Johnson, O., 1961. Reproductive cycle of the mallard duck. Condor, 63, 351-364.

Kirby, J. D., 1996. Spermatogenesis and sperm maturation in male poultry: Targets for improving reproductive performance. Proceedings of the National Breeders Roundtable, 45, 97-109.

Kundu, A. \& J. N. Panda, 1990. Variation on physical characteristics of semen of the white leghorn under hot and humid environment. Indian Journal of Poultry Science, 25, 195-203.

Lin, M., R.C. Jones \& A.W. Blackshaw, 1990. The cycle of the seminiferous epithelium in the Japanese quail (Coturnix coturnix japonica) and estimation of its duration. Journal of Reproduction and Fertility, $\mathbf{8 8}$, 481-490.

Lofts, B., \& R.K. Murton, 1973. Reproduction in birds. In: Avian Biology, eds. Farner D. S., J. R. King \& K. C. Parkes, London Academic Press, pp. 1-107.

Lupold, S., G. Linz, J. Rivers, D. Westneat \& T. Birkhead, 2009. Sperm competition selects beyond relative testes size in birds. Evolution, 63, 391-400.

Marchand, C.R. \&, L. Gomot, 1973. Etude histologique et cytologique des testicules et des voies genitals du canard de Barbarie (Cairina moshata L.) en activite sexuelle. Journées de Recherches Avicoles et Cunicoles, A5, 127-134.

Marchand, C. R \& L. Gomot, 1976. Abortive spermatogenesis in the hybrid duck (cross of male Anas platyrhynchos and female Cairina moschata). Ultrastructural study. Bulletin de l'Association des anatomistes, 60, 613-622.

Maretta, M. \& E. Marretova, 2004. Immunohistochemical demonstration of myoid cells in the testis and its excurrent ducts in the domestic fowls. British Poultry Science, 45, 585-589. 
Marvan, F., 1969. Postnatal development of the male genital tract of the Gallus domesticus. Anatomischer Anzeiger, 124, 443462.

Mirande, C. M., G. F. Gee, A. Burke \& P. Whitlock, 1996. Egg and semen production. In: Cranes: Their Biology, Husbandry, and Conservation, eds. Ellis D. H., G. F. Gee \& C. M. Mirande. Department of the Interior, National Biological Service, Washington, D.C. and the International Crane Foundation, Baraboo, Wisconsin, pp. 45-57.

Mori, G. \& C. George, 1978. Seasonal histological changes in the gonads, thyroid and adrenal of the Canada goose (Branta Canadensis interior). Acta Anatomica, 101, 304-324.

Noirault, J., J. P. Brillard \& M. R. Bakst, 2006. Spermatogenesis in the turkey ( $\mathrm{Me}$ leagridis gallopavo): Quantitative approach in immature and adult males subjected to various photoperiods, Theriogenology, 65, 845-859.

Pakenas, P. I., 1968. The determination of the percentage of the seminal ducts and interstitial tissue in the testes. Arkhiv Anatomii, Gistologii $i$ Embriologii, 55, 110-113 (RU).

Pollock, G., 2002. Avian reproductive anatomy, physiology and endocrinology. Veterinary Clinics of North America: Exotic Animal Practice, 5, 441-474.

Rothwell, B. \& M. D. Tingari, 1973. The ultrastructure of the boundary tissue of the seminiferous tubule in the testis of domes- tic fowl (Gallus domesticus). Journal of Anatomy, 114, 321-328.

Rothwell, B., 1975. Designation of the cellular component of the peritubular boundary tissue of the boundary tissue of the seminiferous tubule in the testis of domestic fowl (Gallus domesticus). British Poultry Science, 16, 527-529.

Trefil, P., A. Micakova, J. Mucksova, J. Hejnar, M. Poplstein, M. R. Bakst, J. Kalina \& J. P. Brillard, 2006. Restoration of spermatogenesis and male fertility by transplantation of dispersed testicular cells in the chicken. Biology of Reproduction, 75, 575-581.

Van Nassauw, L., F. Harrison \& M. Callebaut, 1993. Smooth muscle cells in the peritubular tissue of the quail testis. European Journal of Morphology, 31, 60-64.

Paper received 21.01.2015; accepted for publication 13.03.2015

\section{Correspondence:}

Assoc. Prof. Vasko Gerzilov PhD

Department of Animal Science,

Faculty of Agronomy,

Agricultural University, 4000 Plovdiv, Bulgaria, phone: +359 886000804 , e-mail: v_gerzilov@abv.bg 